\title{
Visiones sobre los tránsitos socio-técnicos hacia patrones de consumo sustentable en agua y energía en la minería sudamericana - dos controversias argentinas
}

\author{
GLORIA BAIGORROTEQUI" \\ GRISTIAN PARKER \\ FERNANDO ESTENSSORO
}

\section{Resumen}

Este trabajo aborda el problema del consumo de agua y energía en la minería sudamericana desde una arista menos explorada: el consumo sustentable. A partir de la sociología y los estudios sociales de la ciencia y la tecnología exponemos esta problemática presentando tres patrones de consumo distintos: convencional, alternativo y progresista. A partir de fuentes secundarias y entrevistas semi-estructuradas hemos rastreado las controversias en torno a dos proyectos mineros históricos argentinos: La Alumbrera y Cerro Vanguardia, focalizando nuestras interrogantes en torno al consumo sustentable de recursos vitales como el agua y la energía. Hemos podido constatar cuán urgente se interpreta la necesidad de transitar hacia patrones de consumo sustentable, quiénes son los llamados a emprenderlos y cuáles precisiones serían necesarias a distintas escalas para efectuar dicha transición. Reconociendo que el agua y la energía son factores constitutivos del tránsito hacia patrones de consumo sustentable en minería, planteamos su centralidad en la gestión de conflictos locales dentro de la gobernanza ambiental latinoamericana. Este estudio forma parte de uno más amplio que abarca varios países sudamericanos. ${ }^{1}$

Palabras-Clave: Patrones de consumo sustentable. Visiones sobre tránsitos socio-técnicos en minería de metales. Agua. Energía. Gobernanza ambiental sudamericana.

\footnotetext{
Instituto de Estudios Avanzados, Universidad de Santiago de Chile.

** Instituto de Estudios Avanzados, Universidad de Santiago de Chile.

*** Instituto de Estudios Avanzados, Universidad de Santiago de Chile.

${ }^{1}$ Agradecemos el apoyo de los proyectos ENGOV Environmental Governance del Séptimo

Programa Marco N²66710 y al proyecto FONDECYT 11121455.
} 
Insights into socio-technical transitions towards patterns of sustainable consumption in water and energy in South-American mining - two Argentinean controversies

\begin{abstract}
This paper addresses the problem of water and energy consumption in the South American mining from a perspective not much explored: the sustainable consumption. From the point of view of sociology and the social studies of science and technology, we expose the issue by presenting three different consumption patterns: conventional, alternative and progressive. Based on both secondary sources and semi-structured interviews, we looked into the controversies surrounding two Argentine historical mining projects: Cerro Vanguardia and La Alumbrera, by focusing our questions around sustainable consumption of resources such as water and energy. We noted the perceived urgency to move towards sustainable consumption patterns, as well as whom are those called to make it happen and what details would be needed at different scales to make the transition. Taking into account that water and energy are fundamental factors for the transition towards sustainable consumption patterns in mining, we propose that they are central to the management of local conflicts in Latin American environmental governance. This study is part of a larger research that encompasses several South American countries.
\end{abstract}

Keywords: sustainable consumption patterns. Views on socio-technical transitions in metal mining. Water. Energy. South American environmental governance.

\title{
1 Introducción
}

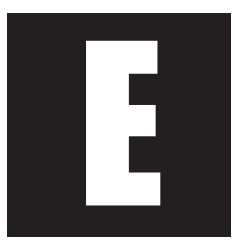

n la trastienda de la sociedad consumista se anclan prácticas de extracción sostenidas, deslocalizadas y masivas de recursos naturales. La minería latinoamericana en su actual fase expansiva bajo el modo de producción neo-extractivista (Gudynas, 2010), post-industrial (Ritzer, 1996, Moulian, 2002) y trasnacional (Martínez-Alier et al., 2010) escasamente ha sido problematizada en términos de consumo sustentable. 
Se critica al modelo neo extractivista en términos sociológicos y políticos a partir de conceptos como los de deuda ecológica (Robleto y Marcelo, 1992), justicia ambiental (Escalona et al., 2011, OLCA, 2011), derechos humanos (OCMAL, 2012, Kemp et al., 2010), derechos indígenas (Yañez y Molina, 2008) que predominan frente al eje discursivo de la sustentabilidad. Otros enfoques críticos hablan de lavado verde (Dahl, 2010, Lim et al., 2013), minería verde (Franks et al., 2013) y consumo verde y sustentable (Böhm et al., 2012). No obstante proponemos aquí zanjar el vacío parcial en cuanto a consumo sustentable. En efecto, en el tratamiento del consumo de agua y energía en minería se juega una capacidad generativa de controversias valóricas (Bebbington et al., 2008), dilemas éticos (Carosio, 2008) y desafíos materiales (Martínez-Alier et al., 2010) que, situados en las controversias sobre el consumo sustentable ${ }^{2}$, nos permitirían acceder también a los supuestos afirmados por quienes son, y pueden llegar a ser, actores sociales estratégicos (Parker y Muñoz, 2012) para justificar o abocar un consumo sustentable fuerte (Lorek y Spangenberg, 2014).

El análisis que proponemos es acerca de la minería en sociedades sudamericanas en desarrollo que por efecto de la globalización son sociedades configuradoras de y configuradas por la tecnología (Tula y Giuliano, 2010, Figueiredo, 1989), junto a sus patrones socio-técnicos (Geels, 2011, Bijker et al., 1987), y socio-culturales (Teixeira de Barros, 2013). Es en ese contexto que a la minería latinoamericana se la puede ver como una práctica privilegiada para despertar del "sonambulismo tecnológico" contemporáneo (Winner, 2008), entendido como la capacidad de determinados sectores de aceptar acríticamente los efectos negativos de las tecnologías extractivas y en cuanto valoración positiva del incremento de artefactos tecnológicos listos para consumir traídos desde los países del Norte.

\footnotetext{
${ }^{2}$ Ver Cohen y Murphy, 2001. Aquí destacamos al consumo sustentable como detonador de controversias sobre la satisfacción de necesidades humanas, y la preocupación, tanto por futuras generaciones como por la distribución social (Baker, 2012, Portilho, 2005).
} 
En este marco, nos planteamos indagar en aquellos discursos, datos, evidencias y percepciones reveladoras de cuán flexibles son las interpretaciones sobre una transformación mayor de los consumos de agua y energía, propios de las prácticas mineras. El objetivo central de la investigación es dilucidar cuán urgente se interpreta la necesidad del tránsito hacia patrones de consumo sustentable, quiénes son los llamados a emprenderlos y cuáles precisiones serían necesarias a distintas escalas para efectuar dicha transición.

La metodología para nuestro estudio, propia del enfoque de transiciones socio-técnicas en multinivel (Geels y Shot, 2007, Geels, 2002, 2005, 2011), se ocupa de rastrear materialmente las evidencias de actores, agencias y procesos surgidos bien de innovaciones, bien de controversias socio-técnicas (Elzen et al., 2011, Geels y Verhees, 2011), las que nos permitirían indagar cómo los hechos se imbrican con valores, creencias, y justificaciones, y en nuestro caso cómo los discursos, las creencias e ideas sobre la tecnología y la naturaleza presentan interpretaciones flexibles (Bijker et al., 1987) y diferenciadas que van configurando determinados tránsitos hacia patrones socio-técnicos articulados alrededor de la noción de consumo sustentable.

Así, a partir de fuentes secundarias y entrevistas semi-estructuradas, hemos rastreado las controversias en torno a dos proyectos argentinos pioneros en la minería metalífera a cielo abierto: La Alumbrera $\left(27^{\circ} 19^{\prime} \mathrm{S}-\right.$ $\left.-66^{\circ} 36^{\prime} \mathrm{O}\right)$ y Cerro Vanguardia $\left(48^{\circ} 23^{\prime} \mathrm{S}-68^{\circ} 16^{\prime} \mathrm{O}\right)^{3}$.

Hemos recopilado información de las respectivas empresas, leyes y normativas argentinas medioambientales orientadas a la minería, así como documentos de organismos latinoamericanos e internacionales, asociaciones empresariales, documentos de ONGs, proyectos de ley,

\footnotetext{
${ }^{3}$ Esta elección considera la posibilidad de rastrar configuraciones socio-técnicas alrededor de la mega-minería metalífera no sólo en Argentina, sino también en Colombia, Chile y Ecuador, por lo tanto, estas controversias nos permiten acceder a datos oficiales sobre el consumo de agua y energía de los proyectos y una trayectoria de intercambios con las localidades de al menos cinco años con estos consumos. Casos reveladores argentinos desde las resistencias locales a la minería a cielo abierto son los proyectos Esquel y Famatina.
} 
Sociologias, Porto Alegre, ano 16, no 37, set/dez 2014, p. 72-111

además de revistas científicas, libros académicos, informes para política pública, libros periodísticos y prensa escrita entre los años 2011 y 2012. A pesar de tratarse de un tema sensible y conflictivo (Bebbington et al., 2008) nuestras fuentes primarias las proveyeron 14 entrevistas semi-estructuradas realizadas durante doce días de septiembre de 2012 dirigidas a los directores de estos proyectos, sus encargados medioambientales, expertos, políticos y representantes ciudadanos críticos a ellos.

A partir de la revisión bibliográfica sobre consumo sustentable se presentaron dos patrones de consumo. Estos patrones fueron contrastados con la revisión de fuentes documentales secundarias, las entrevistas semi-estructuradas y las visitas a terreno efectuadas. Como resultado de esta contrastación se presentó un patrón novedoso de consumo que desbordó descriptivamente a los dos anteriores. En tanto, la perspectiva multinivel permitió la ubicación de artefactos, leyes, certificaciones y visiones en los niveles macro, meso y micro. El acceso a indicadores de consumo, agencias estatales informantes, modalidades de comunicación con las localidades y principalmente las discusiones legislativas y normativas del período nos guiaron en la representación de las visiones sobre tránsitos socio-técnicos de consumo sustentable diferenciado.

\section{Patrones de consumo sustentable en Sudamérica}

Inicialmente distinguimos, dentro de los enfoques sobre consumo sustentable ${ }^{4}$, a dos perspectivas que atienden los vínculos medioambiente-sociedad-política (Estenssoro, 2009) e incluyen en su representación a prácticas de mercado y de no mercado frente a un escenario de Cambio Climático con consecuencias inciertas. Primero, el enfoque de "consumo

\footnotetext{
${ }^{4}$ El consumo sustentable incluye distinciones sobre consumo ético, verde, ecológico, social y solidario. Ver sobre consumo sustentable que interrelacionan naturaleza y cultura en Cohen y Murphy (2001) y sobre sus desafíos en la gobernanza ambiental latinoamericana (Hogenboom, 2012).
} 
Sociologias, Porto Alegre, ano 16, no 37, set/dez 2014, p. 72-111

responsable" vinculado a la noción de individualización del consumidor, a quien se le asigna una responsabilidad específica, y por tanto se le adscribe el deber de responder ante señales de mercado bajo actos imputables; $y$, segundo, el enfoque del "consumo cuidadoso" el cual situamos en la línea de la ética medioambiental, biocéntrica, más vinculado a la preservación de principios precautorios (Rueda, 2004) ante el ritmo extractivo de minerales en la región.

Junto a ellos, teniendo presente los modelos de desarrollo y las prácticas en conflicto de la minería (Svampa y Antonelli, 2010, Vacarezza, 2011), y los aportes de la Nueva Economía que retoma Seyfang (2009), presentamos dos tipos de tránsitos hacia patrones de consumo sustentable en la minería: uno que calificamos como convencional y el otro que calificamos de alternativo.

\subsection{Patrón de consumo sustentable convencional en minería}

Entre los propósitos del consumo sustentable convencional para la minería, se encuentra la necesidad de alcanzar mejoras incrementales en la eficiencia de los recursos agua y energía, y un crecimiento económico continuo a través de "consumir diferenciadamente". Aquí los mecanismos están centrados en cómo los consumidores sustentables de minería envían señales de mercado hacia la producción sustentable de minerales, las cuales redundarían en ajustes en el sector extractivo, regulativo y normativo para responder a esta señales. La representación del consumidor estaría construida sobre aquella compañía verde consumidora de minerales y adscrita a redes de Responsabilidad Social Empresarial (RSE). El progreso normalmente es medido por los mecanismos de crecimiento económico tradicionales y, dependiendo del país, por aquellos mecanismos no tradicionales tales como los de desarrollo limpio, huella de carbono, y huella hídrica.

Las teorías de consumo usadas son utilitaristas y algunas aproximaciones son sociales y sicológicas. Podríamos situar aquí las propuestas de 
Sociologias, Porto Alegre, ano 16, no 37, set/dez 2014, p. 72-111

minería verde sustentable, minería responsable, minería para el pacto global, junto a las técnicas de marketing social y RSE de las mineras frente a las comunidades y sus filiales de origen (WBCSD, 2013, 2000, Parker et al., 2013). Es preciso reconocer que la perspectiva convencional del consumo ha sido criticada por otorgar prioridad a los aspectos económicos y financieros por sobre los modelos enfocados en desarrollo y calidad de vida. En las aproximaciones sobre el consumo responsable situaríamos al consumo sustentable convencional en aquellas empresas, gobiernos, comunidades definidas como responsables de los aprendizajes institucionales y las transformaciones en las infraestructuras de provisión, como las extractivo-mineras, que permitirían los tránsitos hacia patrones de consumo sustentable.

La perspectiva convencional del consumo sustentable reconoce que las compañías mineras se concentrarán en la eficiencia y reducción en el uso de los recursos del agua y la energía en sus procesos, siempre y cuando: resulten deseadas por clientes pertenecientes a mercados verdes interesantes para ellas; sean sujeto de incentivos estatales; les ayuden a mantener el negocio en condiciones de estabilidad con la comunidad circundante; logren mitigar las pérdidas financieras ante escenarios de escasez, o compensar daños ambientales exigidos por las autoridades, o para la salud reclamadas por la población, entre otros ${ }^{5}$.

Leyes, principios y declaraciones programáticas medioambientales requieren de una reforma a partir de reglamentos, protocolos, sistema de control social que vinculen iniciativas deliberativas y participativas en las instituciones públicas nacionales dentro de un marco global. El tránsito hacia un patrón de consumo sustentable convencional en la minería, si bien asume la existencia de sobre-consumidores de recursos naturales, los pre-

\footnotetext{
${ }^{5}$ En línea con los principios de la ética de la responsabilidad (Miranda, 2012) y adaptando los supuestos para el consumo sustentable, propio de la corriente principal "mainstream", presentados por Seyfang (2009: cap. 2).
} 
Sociologias, Porto Alegre, ano 16, no 37, set/dez 2014, p. 72-111

senta capaces de adaptar a tiempo sus prácticas de consumo a las señales de clientes y financistas verdes. El ritmo de este tránsito dependerá de cuán responsables se sientan sus miembros para diferenciarse e innovar en diseños, procesos y tecnologías afines a los horizontes empresariales verdes. El éxito o fracaso se proyecta a partir de la voluntad de agentes individuales racionales y bien informados a distintas escalas: internacionales, regionales, nacionales, federales, locales, etc. para facilitar el ingreso de las innovaciones necesarias en el mercado minero internacional. Rediseños, productos, servicios, procesos requieren aumentar los ahorros en agua, disminuir la intensidad energética, los desechos y disminuir los riesgos de desastres. Claves son los clientes verdes quienes demandan minerales, las empresas deseosas de transitar hacia vías de consumo sustentable, las autoridades abocadas a la supervisión de los consumos, junto a aquellas comunidades abiertas a negociar riesgos, reparaciones y compensaciones.

\subsection{Patrón de consumo sustentable alternativo en minería}

Se trata de un patrón alternativo de consumo, que se basa en la capacidad de grupos, tradicionalmente considerados como consumidores residenciales individuales, de liberarse de las infraestructuras de provisión mineras de ahí su rasgo emancipador al plantear alternativas de no mercado de metales. La noción de consumo sustentable se vincularía a lo que denominamos "consumo cuidadoso" 6 imbricado inextricablemente en prácticas económicas, medioambientales y sociales y, por tanto en donde las prioridades de crecimiento económico se supeditarían a las de

\footnotetext{
${ }^{6}$ Inspirados en la crítica Heideggereana al principio de responsabilidad en la era tecnológica de Hans Jonas hecha por Miranda (2012) concordamos en los límites a la instauración de principios de responsabilidad en la era de los riesgos medioambientales y reconocemos otro tipo de ética, centrada en el cuidado por sobre la responsabilidad que podría transformar las prácticas tecnológicas y sus concomitantes prácticas de consumo sustentable.
} 
Sociologias, Porto Alegre, ano 16, no 37, set/dez 2014, p. 72-111

bienestar socio-ambiental. Las organizaciones económicas y agrupaciones sociales de base y auto-sustentadas son claves para la denuncia ante los impactos negativos de la globalización. Esta perspectiva alternativa acusa al llamado a reducir el consumo por la vía racionalista, propia de la agenda convencional, por considerarla ciega ante los patrones de consumo que sustentan los estilos de vida de las sociedades occidentales (Evans et al., 2002). Las acciones colectivas impulsoras de las transformaciones en infraestructuras promulgan cambios de envergadura en el mercado - consumir menos y, cuando sea necesario, no consumir. Ejemplos son: el incremento de la autosuficiencia, un impacto ambiental bajo, la preservación de la biodiversidad, canales de aprovisionamiento local, campañas de reciclaje, reutilización de minerales insertos en basura digital, basura cero, la denuncia de la obsolescencia programada, entre otros. Se plantea un cambio paradigmático a nivel personal, local y global. El ritmo de este tránsito también dependerá de cuán visibles se hagan las consecuencias no deseadas de la minería en forma de desastres ecológicos, sanitarios, en el número de conflictos locales y movilizaciones cuestionadoras de la minería.

Quienes influirían principalmente hacia este patrón son aquellos consumidores agrupados en redes ciudadanas preservadores de valores ecológicos de sus territorios, junto a los representantes políticos que trabajen en favor de la liberación de esta cadena de consumo dependiente de prácticas mineras intensivas. Las presiones para la transformación provendrían de comunidades ciudadanas ecológicas, economías agrícolas y redes de defensa de los territorios y la biodiversidad. Globalmente se denuncia la dominación económica neo-colonial activada por corporaciones mineras trasnacionales (Evans et al., 2002).

También son importantes los expertos a cargo de la mantención de los sistemas de seguridad de los procesos mineros más contaminantes, del transporte de sustancias peligrosas o del sellado de relaves, porque deben 
Sociologias, Porto Alegre, ano 16, no 37, set/dez 2014, p. 72-111

justificar los desbordes, filtraciones, fallas de mantención, y humanas propias de las consecuencias indeseables de la minería. Asimismo están los reguladores, fiscalizadores, las comunidades interesadas, afectadas, amenazadas, autoridades y expertos en salud y en biodiversidad.

\section{Tres escalas donde situar el tránsito de los patrones}

Previo a presentar las controversias en cuestión y siguiendo la propuesta metodológica de la perspectiva multinivel (Geels, 2005, 2011), que aunque centrada en las innovaciones y transformaciones socio-técnicas en los entramados socio-económicos reconoce tres ejes de representación: micro, meso macro (Geels, 2002), los cuales hemos adaptado para el caso de transformaciones socio-técnicas controvertidas. Esto nos permitiría discriminar horizontes, ritmos de transformación, y sobre quiénes, cómo y porqué se plantean estos tránsitos en referencia al consumo sustentable de agua y energía en la minería.

3.1 Las prácticas mineras a niveles planetarios, internacionales y trasnacionales, no sólo plantean acuerdos, proyectos y alianzas entre países en torno al consumo minero que pujan por más o menos transformaciones en los patrones actuales, sino también determinadas creencias, consciencias, valores, así como actores y agencias que resultarían más relevantes que otras para las transiciones planteadas.

Si bien la presidencia Argentina proyecta posicionarse en la minería metalífera mundial en los próximos años (Secretaría de Minería, 2011) favorecida por el interés de trasnacionales canadienses, australianas y euro-

\footnotetext{
${ }^{7}$ En 2011 los aportes argentinos en la producción de oro mundial correspondieron al 2,38\%, los que podrían considerarse significativos en Latinoamérica, después de las producciones hechas en Perú $(6,3 \%)$, México $(3,4 \%)$, y Brasil $(2,5 \%)$ (BGS, 2013: 27). En lo relativo a la producción de cobre en mina Argentina podría considerarse el quinto país productor en América Latina (Xstrata Copper, 2011, p. 24). De una producción mundial de cobre de mina al año 2011 de 116,7 miles de toneladas de metal, la argentina aportó con un 0,7\% de la producción mundial (BGS, 2013: 19).
} 
Sociologias, Porto Alegre, ano 16, no 37, set/dez 2014, p. 72-111

peas (El inversor minero, 2013), también sus desafíos medioambientales y locales conllevan una politización novedosa de los minerales en la región (Hogenboom, 2012).

Dentro de la minería latinoamericana la presidencia argentina se expone junto a Brasil, México, Colombia, y Chile como uno receptores en 2010 del $81 \%$ de las inversiones extranjeras directas (Secretaría de Minería, 2011) gracias a los Acuerdos de Libre Comercio bilateral, bajo el tratado de comercio MERCOSUR en un escenario de globalización comercial subordinado (Gudynas, 2010).

3.2 Particularmente para los países con regímenes federales o provinciales como Argentina y Colombia, y además de cantones y parroquias contiguas como Ecuador las prácticas mineras requieren lidiar con principios, leyes, normas, políticas y programas muchas de las veces controvertidas en términos nacionales y federales.

Las expectativas y creencias expresadas sobre los cambios en los patrones se relacionan a las referencias hechas al rol del Estado en el desarrollo del país.

Las reservas minerales de la República Argentina y sus proyecciones económicas ${ }^{8}$ la presentan como una Nación con un gobierno ansioso de beneficiarse de la minería con el fin, supuesto, de paliar sus problemas de pobreza (Gudynas, 2010). Es así como sus autoridades proyectan una apertura vertiginosa del país a la raigambre minera de países vecinos como Chile, Perú y Bolivia. Sólo las iniciativas gubernamentales para proteger al mercado nacional y las presiones inflacionarias hacen sombra a los inversores extranjeros (Anglogold-Ashanti, 2012).

${ }^{8}$ Entre 2009-2012 logró un PIB per cápita de 11.452 dólares con una población estimada de 40,1 millones de habitantes, a quienes se les estima una esperanza de vida de 75,2 años, con una alfabetización de 97,4\% (Secretaría de Minería, 211, p. 6). Según los datos de la presidencia el crecimiento de las explotaciones mineras desde 2002 a 2011 fue de un 434\%, Ilegando a 614 proyectos en 2011 (Secretaría de Minería, 2011, p. 2). 
Sociologias, Porto Alegre, ano 16, no 37, set/dez 2014, p. 72-111

Además, como las provincias argentinas son constitucionalmente soberanas de sus recursos naturales ${ }^{9}$, se ciernen controversias en la interpretación de la Carta Magna, donde legislaciones y normativas del Código Nacional de Minería y Energía, se contraponen con las correspondiente al fomento productivo y desarrollo provincial (Constituciones Provinciales, Decretos y leyes provinciales), Ministerios provinciales de fomento productivo, y a su vez, se tensionan frente a las regulaciones, supervisiones, por ejemplo, de policías mineros provinciales, y prescripciones de protección ambiental inscritas en la ley 24.585 de 1995.

3.3 La minería argentina se imbrica a nivel de sus localidades no sólo por medio de los discursos gubernamentales que enfatizan los beneficios económicos, los puestos de trabajo y las medidas de eficiencia y ahorro de agua y energía necesarias (Secretaría de Minería, 2011), sino también gracias a la voz que activa la ciudadanía organizada y los interesados en mostrar la connivencia supuesta entre gobiernos y empresas mineras transnacionales ${ }^{10}$. Por ejemplo, Svampa y Antonelli (2010) reconocen la labor de la sociedad civil, nucleadas desde 2006 en la Unión de Asambleas Ciudadanas (UAC), quienes resisten los esfuerzos de sus autoridades por fundar narrativas desde donde se torne deseable la "Argentina minera".

Las prácticas mineras se muestran vinculadas con gobiernos locales, organizaciones, emprendedores, líderes, grupos de interés. Las interrelaciones cara a cara y cotidianas entre actores son las que permitirían o problematizarían las posibilidades de inclusión social (Thomas, 1999) o conflictividad local (Baigorrotegui, 2013).

\footnotetext{
${ }_{9}^{9}$ El artículo 124 de la constitución argentina especifica "corresponde a las provincias el dominio originario de los recursos naturales existentes en su territorio".

${ }^{10}$ Por ejemplo, la denuncia acerca de las relaciones peligrosas entre los gobiernos kirschneristas con el empresario Mund de la empresa Barrick Gold han configurado incluso el paisaje novelesco del país (Rodríguez, 2009; Bonasso, 2011).
} 
Sociologias, Porto Alegre, ano 16, no 37, set/dez 2014, p. 72-111

Así, por ejemplo, el optimismo gubernamental por explotar la cordillera andina alerta a la ciudadanía de problemas vinculados a la preservación de la identidad local, y surgen problemas como el "paisaje arrancado" (Vacarezza, 2011), y la "criminalización de la protesta" (Walter y Martínez-Alier, 2010).

Estas escalas nos proponen facilitar la presentación de las posibilidades e imposibilidades sobre estos tránsitos. Pero como es bien sabido y a tenor de las críticas al modelo multinivel (Geels, 2011), reconocemos que estas escalas no son entidades reificadas sino espacios traslapados, donde los actores polemizan el alcance de sus acciones en el espacio de lo político (Mouffe, 2009). Las acciones contenciosas (Swyngedouw y Kaika, 2002) junto a la flexibilidad interpretativa posibles de evidenciar en torno a las prácticas de consumo minero interponen una política escalar (MacKinnon, 2011), y por tanto distintas visiones guía para distintos tránsitos (Spät y Rohracher, 2010). Así suponemos la emergencia de dimensiones glocales, geopolíticas, hibridaciones privado-públicas, regulativas y participativas en distintas direcciones.

De este modo, datos, evidencias y la objetividad misma en lo que a minería se trata se entrelaza con valoraciones, percepciones y juicios sobre su tránsito hacia patrones sustentables, que aquí presentamos a partir de rastrear dos proyectos mineros históricos inmersos en controversias por una mayor sustentabilidad.

\section{Dos controversias en torno a la minería a cielo abierto en Argentina}

Los proyectos mineros Minera Alumbrera y Cerro Vanguardia, iniciados en 1997 y 1998 respectivamente, extraen a cielo abierto mayoritariamente cobre, oro, plata y molibdeno. Dentro de los derechos de explotaci- 
Sociologias, Porto Alegre, ano 16, no 37, set/dez 2014, p. 72-111

ón de la Minera Alumbrera un 20\% pertenecen a Yacimientos Mineros de Agua de Dionisio. Además esta sociedad para su explotación se asoció con el gobierno de Catamarca (60\%) y la Universidad Nacional de Tucumán (40\%) (Xstrata Cooper, 2013: 2), y el gobierno nacional (Rodríguez, 2009: 253). Desde mayo de 2013 conforma una de las más grandes compañías del sector al fusionarse con el conglomerado empresarial Glencore.

Parte de la producción de la Alumbrera es madura; las cerca de 521.123 toneladas anuales de metal muestran una caída en la ley del yacimiento, por lo que requiere de mayores consumos de agua y energía para llegar a vetas más profundas que las explotadas en sus años iniciales o explorar nuevas vetas. El precio del cobre permitió que el valor de las exportaciones alcanzase su record en 2012 con 1592 millones de dólares. En 2012 los trabajadores directos eran 1.489 y sus contratistas 1.008 personas (Xstrata Cooper, 2013: 28, 35).

Un año después de La Alumbrera se construyó Cerro Vanguardia, con una inversión de 500 millones de dólares. Actualmente la transnacional británico-sudafricana Anglogold Ashanti posee un 92,5\% de representación accionaria de Cerro Vanguardia y la estatal Fomicruz (Fomento Minero de Santa Cruz) un 7,5\%.

La producción de Cerro Vanguardia para el año 2012 fue de 219.000 onzas de oro con un ingreso de 6,4 billones de dólares. Las reservas declaradas de la empresa son de 2,2 millones de oz/oro, proyectando un horizonte de explotación hasta 2030. Los trabajadores directos de la planta de Cerro Vanguardia son 1.884 y 759 de ellos son contratistas (Anglogold Ashanti, 2012: 3).

El emplazamiento de La Alumbrera incluye cuatro provincias: Catamarca, Tucumán, Santiago del Estero y Santa Fé. En la primera se encuentra el tajo abierto de 2000 metros de diámetro y 800 metros de profundidad. Su dique de colas es una presa de $30 \mathrm{~m}$ de altura y $2,5 \mathrm{~km}^{2}$ de 
Sociologias, Porto Alegre, ano 16, no 37, set/dez 2014, p. 72-111

superficie (Machado, 2010: 208). Este yacimiento cuenta con un tendido eléctrico de 220 KV y $202 \mathrm{Km}$ de extensión y con un mineraloducto de 316 kilómetros, el que incorpora tres plantas de bombeo a lo largo de su recorrido, con un diámetro de $175 \mathrm{~mm}$, el que puede llegar a transportar 100 toneladas por hora, desde la planta hasta aquella de procesamiento de filtros en Tucumán. Allí dos tanques de $2000 \mathrm{~m}^{3}$ cada uno y tres presas de $120 \mathrm{~m}^{2}$, esperan la llegada de una línea ferroviaria de $800 \mathrm{~km}$, la que transporta el concentrado. Los ferrocarriles propios pueden llegar a transportar 10192 toneladas métricas de carga. El transporte continúa hacia el complejo portuario San Lorenzo en la provincia de Santa Fe. Allí pueden llegar a almacenarse 60.000 toneladas métricas.

Por su parte el yacimiento de Cerro Vanguardia de extracción de oro y plata se encuentra ubicado a $150 \mathrm{~km}$ al noreste de San Julián, provincia de Santa Cruz, entre los cerros Vanguardia y el Volcán. La concesión minera alcanza $514 \mathrm{~km}^{2}$, donde lo que se realiza "es extracción a cielo abierto, se utiliza cianuro y se realiza el proceso de lixiviación en carbón para obtener las barras de metal doré" (Bruzzone, 2012: 98). En el terreno existen distintos lugares o pits de extracción simultánea. Desde 2009 la empresa añadió a sus proceso un tratamiento denominado Cianysorb, el que recupera el cianuro en cerca de un 90\% de la solución, e informó una adecuación de la planta para aumentar su producción. Se haría cargo de este incremento su nueva explotación subterránea por realce, tratada por lixiviación en pilas, la que en enero de 2012 entregó 2.800 .000 toneladas de mineral adicionales con leyes de $11 \mathrm{~g} / \mathrm{t}$ de oro. La empresa aspira producir para 2015 cerca de 2.500 .00 onzas de oro a partir de seguir explotando las vetas del área norte, sur y central, añadiendo otros $800 \mathrm{~km}^{2}$ de la propiedad el Volcán (Ibid.). 


\subsection{Consumo de agua y energía en los procesos productivo mineros}

Los consumos declarados de agua y energía por Minera Alumbrera y Cerro Vanguardia para 2012 se presentan métricamente distintos, con un detalle y una accesibilidad mayor en la primera ${ }^{11}$ que en la segunda empresa. Preliminarmente en la tabla 4.1 se observa una mayor eficiencia en el uso de los recursos de agua y energía de Cerro Vanguardia en comparación con La Alumbrera, no obstante el acceso limitado a una plataforma oficial argentina que presente estos datos estandarizados restringe los análisis. Ambos proyectos reconocen consumir menos agua de las permitidas por la administración provincial.

Tabla 4.1 Consumos de agua y energía en la producción de Alumbrera y Cerro Vanguardia en 2012

\begin{tabular}{c|c|c}
\hline \multirow{2}{*}{ Consumo } & La Alumbrera & Cerro Vanguardia \\
& $39.698 .684 \mathrm{t}$ molida & $2.760 .000 \mathrm{t}$ molida \\
\hline \multirow{2}{*}{ Agua } & $20.980 .000 \mathrm{~m}^{3}$ (agua fresca) & $923.104 \mathrm{~m}^{3}$ (agua usada) \\
& $0,528 \mathrm{~m}^{3} / \mathrm{t}$ molida & $0,33 \mathrm{~m}^{3} / \mathrm{molida}$ \\
\hline \multirow{2}{*}{ Energía } & $2.968 .282,8 \mathrm{GJ}$ & $1.600 .000 \mathrm{GJ}$ \\
& $824.523 \mathrm{MW} / \mathrm{h}$ & $444.444 \mathrm{MW} / \mathrm{h}$ \\
\hline
\end{tabular}

Fuente: Elaboración propia en base a Xstrata Cooper, 2013: 66 y 68 y Anglogold Ashanti, 2012: 3. Asumimos que agua fresca en La Alumbrera, sin considerar agua reciclada, es equivalente a agua usada en Cerro Vanguardia.

Las publicaciones oficiales del consumo de agua minero en la Nación Argentina no son accesibles como lo son aquellas por proyecto particular. Por ejemplo, La Cámara Argentina de Empresarios Mineros pro-

\footnotetext{
${ }^{11}$ Minera Alumbrera publica sus informes anuales de sustentabilidad utilizando las metodologías de la Global Reporting Initiative (GRI) en su sitio oficial.
} 
Sociologias, Porto Alegre, ano 16, no 37, set/dez 2014, p. 72-111

pone responder en su sitio oficial las dudas sobre el consumo minero de agua, extrapolando datos de provincias como San Juan para mostrar cuán bajo es el porcentaje del consumo efectivo ante lo permitido por las autoridades y en comparación con otras actividades como la agricultura.

\subsection{Conflictos, desbordes y muertes}

Cuando estallan las crisis, se hacen protagonistas las fugas, fallos humanos y cualquier tipo de desborde fuera de control, por ejemplo, en minería uno de los protagonistas suelen ser los diques de cola ${ }^{12}$. Ni en La Alumbrera ni en Cerro Vanguardia se han librado de desbordes.

En Catamarca, junto con la baja laboral y los impactos ambientales no informados, emergieron los riesgos locales (Vacarezza, 2011). Por ejemplo, fugas en su mineraloducto se constataron en 2001 hacia el río Vis $\mathrm{Vis}^{13}$, en 2004 otras filtraciones acaecieron en su primera estación de bombeo, dos años después se contaminó el río de Villa Vil (Belén) y ese mismo año $3 \mathrm{~km}$ de barro mineralizado contaminaron el río Ampujaco.

Por su parte, llegados a marzo de 2011 en Cerro Vanguardia "la mina sufrió un accidente ambiental cuando el sistema que bombea la pulpa con solución al dique de colas tuvo un pico de presión...con el consecuente vertido del material" (Bruzzone, 2012, p. 101). Lamentablemente, seguido a estos derrames, se acusa una actitud pasiva de las autoridades. Ello no obsta para que éstas expresen palabras de cercanía, como aquellas de la Presidenta Fernández:

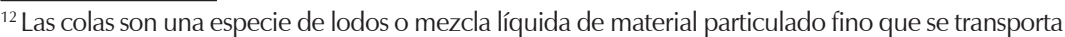
por ductos hacia diques o presas bombeándose o por gravedad, así los diques de cola enclaustran los residuos líquidos de los procesos de producción del material altamente contaminado.

${ }^{13}$ El ingeniero Nieva abrió la polémica sobre los supuestos erróneos realizados en el sistema de filtrado y bombeo de las colas: http://belenresiste.blogspot.com/2006/03/entrevista-alingeniero-hector-nieva.html (19/12/12) y La Alumbrera criticó sus conclusiones: http://www. alumbrera.com.ar/art-001-a.asp (19/12/12).
} 
Sociologias, Porto Alegre, ano 16, no 37, set/dez 2014, p. 72-111

Siento que aquí en Cerro Vanguardia estoy frente a un hijo, porque este modelo de asociación entre una empresa estatal como FOMICRUZ y una empresa privada, es un modelo único que comenzó aquí en Santa Cruz con el gobierno del entonces Gobernador Néstor Kirchner (Panorama Minero, 2012).

Polémicas se ciernen ante la tardía aplicabilidad de la Ley Nacional de Glaciares 26.639 y la ralentización para tratar el proyecto de ley 1855/3 que propone prohibir la minería a cielo abierto.

De hecho, los problemas de gestión financiera y controversias partidistas se enarbolan a la luz de las regalías mineras en sus provincias huéspedes. Durante 2012 el gobernador Daniel Peralta abrió la polémica sobre la insuficiencia de estos aportes financieros (Ámbito Financiero, 2012).

Otro foco de litigios y conflictos surgen por siniestros y muertes laborales. Cerro Vanguardia se ha visto interpelada a tomar medidas de RSE y mejora continua.

\section{Discursos acerca del tránsito hacia patrones de consumo sustentable de agua y energía en la minería}

La entrevista realizada a catorce personas en puestos relevantes en la política, la dirección de empresas mineras y organizaciones de la sociedad civil argentina muestra cómo las transformaciones a distintas escalas urgen o ralentizan los llamados por transformar los patrones de consumo minero actual. Los modelos de desarrollo deseados en Argentina presentan la posibilidad de impulsar, cuestionar y negar su papel dentro del extractivismo minero global.

5.1 Dentro del patrón de consumo sustentable convencional minero globalmente se reconocen los riesgos de explotar los recursos naturales y se deja principalmente en manos de las empresas y el Estado la responsabilidad sobre ellos: 
Sociologias, Porto Alegre, ano 16, no 37, set/dez 2014, p. 72-111

El riesgo social y ambiental van a existir siempre. No existe el riesgo cero. Entonces es responsabilidad tanto de las empresas como de las autoridades, cómo implementar, cómo desarrollar, cómo hacer el gerenciamiento de los proyectos para que puedan satisfacer todo ese cúmulo de requerimientos, de necesidades y de inquietudes que tiene la sociedad en torno... a la minería (encargado $\mathrm{MA}_{2}$ ).

Interesa aquí el aprovechamiento de una minería estatal: "A mi me gustaría un minera estatal, con un alto grado de derrame social" (Asesor técnico-político ${ }_{2}$ )

Desde esta perspectiva, a nivel nacional se reconocen "...emprendimientos..el uso de otras aguas que no compitan ...con el agua de consumo humano" (asesor de político $)$ y de tecnologías afines que permitan la coexistencia:

Nosotros hoy estamos haciendo una optimización de ese consumo, porque el agua que va a ese proceso, va de nuevo a bombear...estamos consumiendo entre setenta y cinco a ochenta metros cúbicos...Siempre estamos por debajo de lo autorizado (encargado Minera $)_{1}$.

Con respecto al consumo de energía un encargado de gobierno reconoce que:

Nosotros pensamos que parte de la energía de estos proyectos tiene que ser energía limpia. Tienen que substituir sus motores por energías renovables... Va a avanzar la tecnología (Director gubernamental).

No obstante los entrevistados presentaron como desafiante la fiscalización desde los políticos y reguladores para hacer valer las leyes medioambientales en minería:

Deberíamos ser mucho más duros con las normas ...y con el cumplimiento de esas normas, eh, con los controles que la gente, que el Estado debe ejercer (Encarg. MA). 
Sociologias, Porto Alegre, ano 16, no 37, set/dez 2014, p. 72-111

Localmente las resistencias se perciben como falta de información de las personas: Si esta gente se informara cómo se está manejando... conociera las leyes... no tendríamos ese problema (encargado MA minera ${ }_{1}$ ). Aunque también se percibe mayor involucramiento de las localidades: Me parece que ahora hay mucha más voluntad de participar, nosotros desde Fomicruz hemos trabajado ...con la asamblea ambiental (Encargada MA minera). Aquellas localidades vecinas a mineras reconvertidas son presentadas como ejemplares en la coexistencia minería y agricultura local:

\begin{abstract}
Y alrededor se vio que había comunidades que vivían del cultivo tradicional, de la vid, del olivo... han hecho una evaluación del tema... Entonces cambiaron las cepas, lo mismo hicieron con las nueces, y lograron que esas comunidades no sólo tengan una producción minera, sino en lo que les es propio, que son estos cultivos... centenarios (Director gubernamental).
\end{abstract}

El patrón convencional aloja principalmente a los discursos de directores de proyectos mineros trasnacionales y federales, asesores, directores y autoridades gubernamentales, quienes conciben la coexistencia con las prácticas locales negociadas, con compensaciones de todo tipo. El tránsito hacia un patrón de consumo sustentable es claro aunque su ritmo se supedita al desarrollo económico y financiero para las regiones, junto a la adquisición de tecnología de punta, y la concreción de controles y fiscalizaciones necesarias. Las controversias en torno al consumo de agua y energía de la minería se presentan gestionadas por medio de la inclusión gradual de innovaciones en el entramado institucional y tecnológico. Aunque las controversias más álgidas han sido por los derrames y desbordes de los efluentes de ambas mineras, la desconfianza pública se cierne ante la falta de transparencia en el consumo y calidad del agua y sobre las medidas de eficiencia energética incorporada en sus instalaciones.

Minera la Alumbrera, ante estas inquietudes, presenta sus datos de consumo de agua y energía anuales en sus reportes de sustentabilidad. 
Sociologias, Porto Alegre, ano 16, no 37, set/dez 2014, p. 72-111

Desde que la transnacional Xstrata-Copper adoptó voluntariamente los acuerdos del Pacto Global de las Naciones Unidas, el cumplimiento de su estrategia de Desarrollo Sustentable y el logro de certificaciones ISO 90001 y 14001 fueron difundidos en este periodo. El acento en la reutilización del agua de acuífero El Arenal y la eficiencia energética de los procesos, por ejemplo, priorizando la energía hidroeléctrica, se destacan en su informe del año 2011, período en que la falta de informes que den cuenta de la contaminación del valle se hizo evidente (Machado et al., 2011). Sin prejuicio de lo anterior, mandatada por La Alumbrera, la Universidad Nacional de Tucumán prosiguió sus estudios sobre la contaminación de la cuenca del río Vis Vis. La empresa destacó el modelamiento matemático de Campo Arenal sobre la hidrología de la cuenca e implementó un sistema de retrobombeo del agua para evitar el consumo agua fresca (Xstrata Copper, 2011).

En términos del régimen minero argentino, se gestiona la aplicación y supervisión de la ley de la Nación ambiental minera 24.585, como capítulo del código Minero de 1990, la que obliga a las empresas a presentar Informes de Impacto Ambiental y no Evaluaciones de Impacto Ambiental. Esto podría re-abrir el debate por los principios considerados en esta ley y por las definiciones de daño ambiental incluidos en ella (Machado et al., 2011). La preservación de recursos inter-jurisdiccionales como el agua, en este caso se plantean problemáticos.

Cerro Vanguardia, por su parte, en su sitio internet oficial reconoce la reutilización del agua que extrae de un acuífero y lagunas cercanas. Además añade que sólo ocupa el $68 \%$ del volumen de agua total autorizado por la provincia. Junto a la reutilización del agua, la empresa reconoció la utilización de bioindicadores como la cría de truchas en las lagunas adyacentes, dentro del yacimiento, además de la reinyección de agua en la zona de campo de pozos. La siguiente tabla propone esquematizar estos vínculos. 
Sociologias, Porto Alegre, ano 16, no 37, set/dez 2014, p. 72-111

Tabla 5.1 Vínculos tránsito socio-técnicos convencional

\begin{tabular}{|c|c|c|c|c|}
\hline $\begin{array}{l}\text { Tránsito hacia } \\
\text { patrones de } \\
\text { consumo - Flexibi- } \\
\text { lidad interpretativa }\end{array}$ & $\begin{array}{l}\text { Urgencia } \\
\text { tránsito S-T }\end{array}$ & $\begin{array}{c}\text { Gestión } \\
\text { controversias } \\
\text { socio-técnicas } \\
\text { principales }\end{array}$ & $\begin{array}{c}\text { Grupos Sociales } \\
\text { Relevantes - Actores } \\
\text { Estratégicos }\end{array}$ & $\begin{array}{l}\text { Innovaciones } \\
\text { Multi-Nivel }\end{array}$ \\
\hline Convencional & $\begin{array}{l}\text { Media - } \\
\text { relativa a los } \\
\text { indicadores de } \\
\text { crecimiento } \\
\text { socio-econó- } \\
\text { micos }\end{array}$ & Mantenida & $\begin{array}{l}\text { Ejecutivos mineras, } \\
\text { gobierno, políticos } \\
\text { supervisores nacio- } \\
\text { nales, federales y } \\
\text { expertos }\end{array}$ & $\begin{array}{l}\text { Macro: ISO, RSE, Pac- } \\
\text { to Global ONU Meso: } \\
\text { Mejora fiscalización } \\
\text { y normativa, Actua- } \\
\text { lización ley 24.585, } \\
\text { Eficiencia Energética, } \\
\text { Micro: Estrategias De- } \\
\text { sarrollo Sustentable, } \\
\text { Reutilización agua } \\
\text { procesos, Relaciones } \\
\text { comunitarias }\end{array}$ \\
\hline
\end{tabular}

Algo más escépticos resultan los planteamientos alternativos, los que en sí presentan cambios paradigmáticos, aunque que para el caso Argentino requeriría de precisiones.

5.2. Desde el patrón alternativo en la minería el tránsito hacia un consumo sustentable de agua y energía es prioritario:

Tenemos que tener en cuenta que estamos en un momento de emergencia planetaria, de crisis última... vamos a seguir avalando este consumismo desbocado, que avalan las corporaciones...los gobiernos cómplices, o si vamos realmente a cambiar de paradigma y pensar qué consumir... se deben repensar ..el consumismo hipnótico ... que nos lleva a sacar desbocadamente metales (Representante $\mathrm{ONG}_{1}$ ).

Aunque no se llamó a consumir menos, sí se planteó en uno de los entrevistados el dilema que acarrea: "El crecimiento es/debe ser limitado y creo que hoy estamos en una disyuntiva que tenemos que resolver" (Diputado de la Nación). A este respecto una representante rechaza una producción minera abiertamente: 
Sociologias, Porto Alegre, ano 16, no 37, set/dez 2014, p. 72-111

...aunque nos digan que la mega-minería de cielo abierto fuera manejada, en vez de las corporaciones por el Estado, nosotros les diríamos que no... Si fuera minería en pequeña escala, una minería que, bueno que impacta, pero que es mucho menor, estaríamos abiertos a reflexionar cual sería la forma regulatoria más conveniente. (Representante ONG $\mathrm{N}_{1}$.

Se desconfía en que los mecanismos de mercado actual puedan adaptarse a los desafíos de emergencia hídrica planetaria: pagando solamente no se puede sobrellevar una situación de uso desmedido de un recurso o de contaminación, no solamente pagando, tenemos que prevenir, tenemos que cuidar más (Encargada MA minera).

El consumo de agua y energía es visto como sobreconsumo por parte de la minería y como una medida de justicia para las comunidades afectadas por empresas foráneas: El agua está siendo destinada a las trasnacionales, como las corporaciones mega-mineras. Después los pequeños campesino no tiene agua para regar sus cultivos (Representante $\mathrm{ONG}_{1}$ ).

Si bien un cambio alternativo del mercado reconoce economías alternativas un entrevistado mostró preocupación por la incompatibilidad de la minería con ellas:

Nosotros viajamos mucho a los terrenos afectados como a Cajamarca, y ellos nos comentaban como ellos tiene precios internacionales, con especificaciones para los cultivos orgánicos. Y hoy en día tienen montón de pérdidas en sus territorios ide agua! O sea, tienen río secos, contaminados....en muchos sectores ya no pueden cultivar (representante ONG).

Los umbrales de consumo energético minero contrastados con los de las localidades se polemizan. Machado destaca que el consumo eléctrico de la minera Alumbrera en 2003 equivalió a 170\% del total del consumo de la provincia de Catamarca (Machado, 2010: 210). Y una entrevistada desconfía de los objetivos para la Integración de la Infraestructura Regional Sudamericana (IIRSA) como plan generan las represas 
energéticas que ellos necesitan, que generan las rutas para llevarse los minerales... la instalan diciendo que es para el progreso y el desarrollo de la región sudamericana (Representante $\mathrm{ONG}_{1}$ ).

Los problemas de salud conforman los riesgos de las localidades y sólo un entrevistado reconoció el problema de los diques de colas en contraste con el uso de cianuro o la minería radioactiva:

... los grandes impactos o pasivos por lo menos que dejan, este, los cuales son bombas de tiempo, bombas químicas de tiempo, son los piques de cobre los cuales quedan concentrados todos los metales de desechos que no son utilizados dentro del proceso... estas leyes que habíamos hablado al principio, permisivas dejan que estos diques de cola queden abandonados al termino de la explotación sin ningún tipo de señalamiento (representante asamblea ciudadana).

Ahora bien, aparentemente lo emancipador y alternativo de este tránsito podría sintonizar en tono de urgencia cuando los entrevistados reconocen su labor personal y pública en ello. No obstante las propuestas traducidas en prácticas comunitarias, provenientes de ciudadanos organizados a favor de alternativas frente al consumo de materiales no fueron mayoritariamente evidenciadas en nuestras entrevistas, pero sí en algunos documentos de los grupos activistas. Mayoritariamente se concibe la labor de denuncia frente al Estado para salvaguardar los derechos y deberes frente a sus localidades, en otras palabras, se plantea la escalada en la visibilidad de estas controversias, dados los impactos en los territorios afectados irreversiblemente. En el paisaje socio-técnico de este tránsito, a nivel macro, predominan los acuerdos internacionales del Panel Intergubernamental de Cambio Climático, el cual para Latinoamérica reconoce los planteamientos de la Cumbre de Río 92 y el marco de Derechos Humanos y Derechos sociales de la ONU. 
Sociologias, Porto Alegre, ano 16, no 37, set/dez 2014, p. 72-111

La falta de una perspectiva nacional e inter-jurisdiccional del consumo de agua resulta clave, en especial la inclusión de los principios preventivos, precautorios y los de sustentabilidad otorgados en la ley 25.675, según Machado et al. (2011) más exigente que la ley ambiental vigente para la minería. Para estos autores las controversias ciudadanas sobre el consumo de agua minero ponen en cuestión la fiscalización de las tareas mineras. La lejanía y las condiciones extremas en donde se encuentran fiscalizadores y mineros hacen poco fiable su rigor en el proceso de control.

La preservación de glaciares y la gestión de unidades ecológicas por cuenca han sido iniciativas legislativas resistidas por los gobiernos Federales, quienes con el apoyo de Cristina Fernández han interpuestos decretos excepcionales a la implementación de esta ley. Para el caso de Minera La Alumbrera se han denunciado relaciones clientelares en las localidades, mientras que para el caso de Cerro Vanguardia se destacan los problemas de fiscalización. En entrevista con un representante de ONGs de la provincia de Santa Cruz en 2012 comentó que: "el ultimo policía minero, este, digamos fiscalizador, contralor de la actividad minera había pasado y hacia ocho meses que había ido la última vez, en ese momento había sólo un policía minero para toda la provincia de Santa Cruz". Junto a estas deficiencias se cuestiona la necesidad de mayor transparencia en torno a los datos de consumo de agua de la minera. Para Bruzzone (2012) el consumo declarado desde la Secretaría de Energía de la Nación para la minera fluctuaría entre 90 y 110 millones de litros al mes, lo cual supera a lo declarado en promedio por la empresa para el año 2012 (ver tabla 4.1).

El proyecto de ley para frenar la megaminería metalífera, por ejemplo, por la vía de consultas ciudadanas es lo que se propone desde este patrón. 
Sociologias, Porto Alegre, ano 16, no 37, set/dez 2014, p. 72-111

Tabla 5.2 Vínculos tránsito socio-técnicos alternativos

\begin{tabular}{|c|c|c|c|c|}
\hline $\begin{array}{l}\text { Tránsito hacia } \\
\text { patrones de } \\
\text { consumo - } \\
\text { Flexibilidad } \\
\text { interpretativa }\end{array}$ & $\begin{array}{l}\text { Urgencia } \\
\text { tránsito S-T }\end{array}$ & $\begin{array}{c}\text { Gestión } \\
\text { controversias } \\
\text { socio-técnicas } \\
\text { principales }\end{array}$ & $\begin{array}{c}\text { Grupos Sociales } \\
\text { Relevantes } \\
\text { - Actores } \\
\text { Estratégicos }\end{array}$ & $\begin{array}{l}\text { Innovaciones } \\
\text { Multi-Nivel }\end{array}$ \\
\hline Alternativa & $\begin{array}{c}\text { Alta - relativa a } \\
\text { los escenarios } \\
\text { del Cambio } \\
\text { Climático }\end{array}$ & En escalada & $\begin{array}{l}\text { Políticos, repre- } \\
\text { sentantes de } \\
\text { ONGs, grupos } \\
\text { movilizados, } \\
\text { contra-exper- } \\
\text { ticia }\end{array}$ & $\begin{array}{c}\text { Macro: Protocolo } \\
\text { Kioto, Cumbre de } \\
\text { Río 92. Meso: Ley } \\
\text { Nacional ambien- } \\
\text { tal 25. } 675 \text { para } \\
\text { la minería, Efi- } \\
\text { ciencia Energética, } \\
\text { Energías Renova- } \\
\text { bles, Seguros ante } \\
\text { desastres } \\
\text { Micro: Consulta } \\
\text { ciudadanas pre- } \\
\text { vias, Asambleas } \\
\text { Ciudadanas }\end{array}$ \\
\hline
\end{tabular}

Junto a estos dos patrones de consumo sustentable identificados presentaremos un tercer patrón: el patrón de consumo sustentable progresista, surgido a partir de las entrevistas y los estudios acerca de la minería latinoamericana (Gudynas, 2010; Bebbington et al., 2008) y la Argentina en particular (Vacarezza, 2011; Rodríguez, 2009; Svampa y Antonelli, 2010).

5.3 Un tránsito progresista de patrón de consumo sustentable minero se constató en aquella justificación que niega un sobre-consumo de agua y energía, porque se presentan balanceados en ciclos planetarios de transformación: Esa agua se va a las nubes, y las nubes después precipitan, el ciclo del agua... lo que regula el agua son las precipitaciones... (Director minera ${ }_{1}$ ). Se evade el término consumo a escala planetaria debido a que ni el agua ni la energía de la minería se agotarín en la tierra, sino que se transformarían: No la consume [agua], la usa...y la recicla...o sea no hay una desaparición del agua... la actividad minera genera su propia energía, y si no utiliza los sistemas de las redes nacionales, pero... iestá en balance! (Director minera). 
Sociologias, Porto Alegre, ano 16, no 37, set/dez 2014, p. 72-111

En este patrón, el crecimiento en el uso de los recursos es indiscutible y un entrevistado desconfió de las instancias científicas internacionales: "Yo no creo en el cambio climático...o sea, no creo en el efecto invernadero...el hombre tiende a establecer parámetros en base a lo que tiene registro. Y esos registros los tiene desde un tiempo muy finito" (Director Minera ${ }_{1}$ ). Esta incredulidad se conecta con que las transformaciones se plantean cautelosas para Argentina debido a que la disponibilidad de agua y energía para la minería sería vital, dada la necesidad antropocéntrica de los metales, como expone la presidenta Fernández: Es imposible prescindir de la minería, pero no solamente desde los lugares comunes como un aro, un auto, los celulares, de todo, hasta para los remedios se necesita de minerales (Panorama Minero, 2012).

Nacional, provincial y localmente las empresas y el gobierno deben asegurar que las empresas adquieran tecnología novedosa y las localidades se capaciten en ellas con el fin de que este uso de recursos no se concrete como consumo, y así se agoten las fuentes locales que geográficamente sustentan operativamente la minería. Seguramente se agotarán en este punto, pero localmente... podrá haber un agotamiento, por supuesto, obvio. Pero la posibilidad de acceder a cobre de baja ley es enorme. De hecho, hay minerales que se reciclan (Director Minera ${ }_{1}$ ).

El progreso de las localidades se vincula con la acción de las empresas y la fiscalización:

Una economía que deja unos pueblos fantasmas y sólo produce pesadumbre, es una economía que no progresa. Nosotros trabajamos bajo un esquema en que hablamos de desarrollo sustentable; es decir, que haya actividad económica más allá del cierre de la mina, más allá del ciclo productivo de ésta... Creemos que la actividad nuestra, para muchas zonas, es una actividad casi imprescindible que debe ejecutarse, pero siempre siguiendo no sólo las normas sino los controles que fija tanto el Estado como 
Sociologias, Porto Alegre, ano 16, no 37, set/dez 2014, p. 72-111

las propias comunidades, para que el impacto de una actividad minera pueda ser mitigado, pueda ser remediado (Director gubernamental).

Se observa, como lo adelanta Castells (2006), un discurso ambiguo sobre las preocupaciones medioambientales, ya sea porque la minera se presenta usando y no consumiendo agua y energía, o porque se adscribe la necesidad de que Autoridades y las empresas sean responsables de su accionar en marcos de sustentabilidad, muy en línea con el patrón de consumo convencional.

En la siguiente tabla se sintetiza el tránsito no requerido de una urgencia especial debido a que obedecería al desarrollo natural del progreso científico tecnológico de la minería. Las controversias en torno a su consumo de agua y energía resultarían clausuradas por los directivos mineros responsables socialmente, y por la interposición de leyes como la ley ambiental minera 24.585, considerada suficiente para la regulación del sector. Ni La Alumbrera ni en Cerro Vanguardia se declaran fuera de la observancia ambiental y los directivos del sector minero argentino reconocen las actividades mineras como compatibles con otras actividades a su alrededor.

La Alumbrera, en 2011, promovió encuestas en las provincias afectadas directamente por sus actividades, mitigó impactos y generó programas compensatorios con las comunidades por medio de regalías mineras. Por ejemplo, después de haber recibido reclamos formales por derechos de agua en predios aledaños, la empresa se involucró en un emprendimiento asociativo de los comuneros quienes reconvirtieron sus labores ganaderas en plantaciones de olivos y otras especies locales (Xstrata Copper, 2011).

Cerro Vanguardia, distinguida como la empresa minera del año 2011, en sus boletines Oro del Sur informó sobre los procesos de mejora continua y estrategias de prevención de accidentes durante 2011 y 2012. Ante las inquietudes ciudadanas sobre su consumo de agua, la empre- 
Sociologias, Porto Alegre, ano 16, no 37, set/dez 2014, p. 72-111

sa, desde 2009, añadió al monitoreo participativo de la calidad del agua con personas de Puerto San Julián, nuevos platos en el restaurant de la empresa: Alevines o truchas sembradas en la laguna del Carbón. Si bien dio comienzo a la explotación de mineral por pilas de lixiviación en sus procesos, reconoció su intención de incorporar un sistema de trazabilidad hídrica y presentó su membrecía a la código de gestión de cianuro (Anglogold Ashanti, 2012). En 2012 la presidenta Fernández visitó sus instalaciones. Allí junto a las especies conservadas en los terrenos del yacimiento reconoció a Cerro Vanguardia como ejemplo de minería sustentable.

Tabla 5.3 Vínculos tránsito socio-técnicos progresista

\begin{tabular}{|c|c|c|c|c|}
\hline $\begin{array}{l}\text { Tránsito hacia } \\
\text { patrones de } \\
\text { consumo- } \\
\text { Flexibilidad } \\
\text { interpretativa }\end{array}$ & $\begin{array}{l}\text { Urgencia } \\
\text { tránsito S-T }\end{array}$ & $\begin{array}{c}\text { Gestión } \\
\text { controversias } \\
\text { socio-técnicas } \\
\text { principales }\end{array}$ & $\begin{array}{c}\text { Grupos } \\
\text { Sociales } \\
\text { Relevantes - } \\
\text { Actores } \\
\text { Estratégicos }\end{array}$ & $\begin{array}{l}\text { Innovaciones } \\
\text { Multi-Nivel }\end{array}$ \\
\hline Progresista & $\begin{array}{c}\text { Baja - relativa } \\
\text { a los ritmos } \\
\text { naturales } \\
\text { del progreso } \\
\text { científico } \\
\text { tecnológico }\end{array}$ & Clausurada & $\begin{array}{c}\text { Ejecutivos mi- } \\
\text { neras, gobier- } \\
\text { no, políticos } \\
\text { supervisores } \\
\text { nacionales, } \\
\text { federales y } \\
\text { expertos }\end{array}$ & $\begin{array}{c}\text { Macro: Aprovecha- } \\
\text { miento y eficiencia de } \\
\text { agua y energía. ISO. } \\
\text { RSE. } \\
\text { Meso: Preservación } \\
\text { ley 24.585, Eficiencia } \\
\text { Energética, } \\
\text { Micro: Estrategias De- } \\
\text { sarrollo Sustentable, } \\
\text { Reutilización agua } \\
\text { procesos, Relaciones } \\
\text { comunitarias basadas } \\
\text { en la idea de trabajo y } \\
\text { progreso }\end{array}$ \\
\hline
\end{tabular}

6. Tres y no dos patrones: el patrón de consumo sustentable progresista en minería

El patrón de consumo sustentable basado en la idea de progreso o progresista, si bien no niega los discursos acerca de la sustentabilidad, entra en

http://dx.doi.org/10.1590/15174522-016003704 
algunas contradicciones que podrían presentarlo como un patrón insustentable, por ejemplo, no asume la finitud del agua y la energía. Además, en este patrón se plantea incredulidad ante la gravedad del cambio climático, cuestión que sí reconoce el consumo sustentable convencional de la minería.

Igualmente, si bien comparte la necesidad de responder del modo más barato posible a las exigencias internacionales sobre la sustentabilidad y el sector del mercado verde, no reconoce una verdadera urgencia para transformar los mecanismos de las infraestructuras de provisión. Esto lo ubica en antípodas del patrón de consumo sustentable alternativo. Este patrón progresista se asienta en la dependencia antropológica del ser humano de los minerales, es decir, no concibe una proyección sin explotación de minerales, y confía abiertamente en la posibilidad de que las capacidades tecnológicas lleven al ser humano a extraer minerales en lugares hasta ahora insondables.

La minería se sitúa como una actividad dirigida nacionalmente hacia la superación de la pobreza de los países en desarrollo desde narrativas progresistas (Antonelli, 2010). Los profesionales formados en la verderización de la minería son cruciales en la coexistencia de esta minería en regiones específicas. El ahorro y eficiencia en el uso del agua y la energía se valoran positivamente como fases en el proceso incuestionable del progreso minero, especialmente en términos de la gran escala e intensidad de sus explotaciones.

Aunque se reconocen los problemas con las comunidades que alegan la preservación de sus prácticas tradicionales, el patrón de consumo sustentable progresista plantea su coexistencia negociada con ellas. Los promotores de este patrón reclaman inversiones altas para la instalación de mineras de gran escala sin discriminación en la explotación y desde cualquier parte del mundo.

El tránsito hacia un patrón de consumo sustentable progresista en la minería tiene el supuesto de que los países aventajados por poseer minerales en 
Sociologias, Porto Alegre, ano 16, no 37, set/dez 2014, p. 72-111

su cordillera deben explotarlos para desarrollarse. Es un llamado a ser conscientes sobre las posibilidades de desarrollo que se ciernen bajo la cordillera.

El llamado de los directores de empresas mineras, políticos a favor de la producción industrial, reguladores del sector energético, lobistas es a insertarse urgentemente al mercado de los commodities, aprovechar los recursos minerales con sustentabilidad. La coexistencia pacífica con otras modalidades de consumo conlleva serias contradicciones dado que no permite renunciar al liderazgo exportador de minerales y al progreso minero internacional.

El ritmo de la transición en el país huésped se imprime en los deseos de las autoridades y empresarios locales de transformarse en líderes del negocio minero, y con ello que la cadena de intereses de las elites locales e internacionales de la minería reciban condiciones de estabilidad macroeconómicas para la puesta en marcha de este tipo de infraestructuras de provisión.

\section{Conclusiones}

A partir de la revisión bibliográfica sobre consumo de sistemas de provisión y las fuentes secundarias pudimos distinguir entre consumo sustentable "responsable" y el consumo sustentable "cuidadoso", gracias a los cuales articulamos dos patrones de consumo socio-técnico para la minería; uno convencional y otro alternativo y confirmamos que ninguno de nuestros entrevistados negó la necesidad de transitar hacia vías de consumo sustentable de agua y energía en minería, en otras palabras, constatamos que en el paisaje socio-técnico de la minería sudamericana la noción de sustentabilidad está incluida, aunque de forma problemática. Esto último dado que constatamos, además, un nuevo patrón de consumo sustentable; el progresista, que catalogamos al límite de lo que el término sustentabilidad permitiría. Esta situación enciende la alarma 
debido a la dificultad para acceder a una plataforma oficial que gestione los datos de consumo de agua y energía en la minería Argentina.

Al igual que Parker et al. (2013) observamos preferencias en torno a escalas temporales para las transiciones desde cada patrón de consumo. Mientras el patrón de consumo sustentable alternativo aboga por la inminencia de las decisiones políticas y regulativas en una perspectiva de largo aliento, el patrón progresista expone cautela y no urge la necesidad de los tránsitos, en parte compartiendo evidencias con los patrones convencionales, desde donde se interpela a la acción en el mediano plazo, jalado por, entre otros, aritméticas electorales, oportunidades de ingresar tecnologías ecoeficientes y posibilidades de consenso entre las elites mineras ante las presiones por mayor sustentabilidad.

La adaptación de las tres escalas para la presentación, propia de la perspectiva multinivel, más abocada al ingreso de innovaciones en los mercados, fue fructífera en este caso, dado que la asumimos como un tipo de "política escalar", donde pudiesen representarse controversias por los significados de estos tránsitos. El rastreo material de controversias sobre el consumo expuso la necesidad de tipificar al menos tres tránsitos, los cuales a modo de flexibilidades interpretativas adelantan controversias socio técnicas consideradas como: gestionadas, en escalada y clausuradas.

Un tránsito único quedó descartado en este trabajo. Los flancos legislativos, regulativos y normativos abiertos son las principales controversias socio-técnicas para la instauración de más o menos innovaciones tecnológicas para el consumo sustentable de agua y energía en la minería en Argentina. Hasta ahora las tecnologías de eficiencia y ahorro de agua y energía se enmarcan dentro de los principios de las empresas transnacionales y sus pactos de comportamiento ético para con los países donde se alojan. Cerro Vanguardia ha tenido un protagonismo con la comunicación de las localidades más cercanas, no obstante, los datos específicos son 
Sociologias, Porto Alegre, ano 16, no 37, set/dez 2014, p. 72-111

menos accesibles que para el caso de La Alumbrera, con un historial más controvertido medioambientalmente.

Nuestra propuesta enriquece las críticas en torno a la existencia de un tránsito socio-técnico exclusivo (Geels, 2011) y reconocemos en Argentina más bien distintas visiones guías de estos tránsitos hacia futuros socio-técnicos deseados, los que coexisten y compiten entre sí (Späth y Rohracher, 2010). Ahora bien, la cercanía entre los patrones convencionales y progresistas podría poner en riesgo la versión de un patrón de consumo sustentable cuidadoso del agua y la energía para gestionarlo en términos de responsabilidad social. Esto porque en las discusiones legislativas para la minería argentina los principios precautorios y de sustentabilidad se encuentran supeditados a los de la compensación y mitigación de impactos ambientales en el código minero (Machado et al., 2011).

De este modo la flexibilidad interpretativa se vincularía con cuán intensamente incorporada esté la noción de sustentabilidad en su visión sobre el tránsito socio-técnico deseado, y cuan próximos se encuentren esos actores a los patrones institucionales de la minería. Esto porque las principales controversias del período examinado estuvieron focalizadas en cambios legislativos, normativos y de supervisión.

Las relaciones global, regional e internacional resultaron importantísimas para el tránsito hacia patrones de consumo sustentable en modalidad progresista y convencional, debido a que, por ejemplo, los entrevistados considerados participan directamente de negocios trasnacionales y activan regulaciones que traslapan los intereses territoriales nacionales con los de las corporaciones mineras. La escala glocal influyó especialmente en el patrón alternativo para mostrar cómo lo local se vincula a lo global aunque aún no constatamos traducciones dentro de las lógicas del mercado minero, o dentro de opciones alternativas de no mercado de minerales. Asimismo, dada la arremetida progresista argentina, las autoridades tornarían asimétricas las 
estrategias de defensa territoriales, y sospechosas cualquier propuesta de "no consumo" y "decrecimiento" para América Latina.

El tránsito mirado desde los modos progresista y alternativo proyecta espacios divergentes y problemáticos. Se proyectan conflictos entre perspectivas antagónicas, aunque coincidentes en la necesidad de transitar hacia patrones de consumo sustentable. La discusión y la crítica álgida de las leyes de protección de recursos naturales, además de la visibilidad de las luchas locales ponen en jaque las perspectivas optimistas en torno al restablecimiento cíclico del agua y la energía a nivel global o en torno al uso eficiente del agua en la minería. Existe una fe incuestionable en el mercado y la tecnología desde la perspectiva progresista y una desconfianza profunda hacia esos factores desde el patrón alternativo. Es por ello que quienes resultan estratégicos para las transformaciones son las autoridades estatales, y por consiguiente la visión convencional, en el marco de la economía de intercambios hacia la cual cada patrón propone transitar, resulta crucial en términos de traducciones, mediaciones y deliberaciones entre las otras dos perspectivas. Aquí el Estado Argentino está interpelado a mejorar los mecanismos participativos con las localidades.

La necesidad de traducir las demandas hacia patrones de consumo sustentable en términos convencionales podría favorecer una mediación entre directivos de empresas mineras, políticos y legisladores progresistas, quienes requerirían conocer los aportes de la ecología política, la gestión integrada de recursos naturales, mantención de ecosistemas y reconocer los desafíos para la salud pública, el marco de derechos y la democratización de las decisiones sobre la minería, y por otro lado las comunidades preocupadas, interesadas y amenazadas, quienes considerando los esfuerzos materiales para transitar hacia vías más sustentables de consumo de metales, podrían traducir aún más propuestas desde consumidores, y no-consumidores de minerales, afines a las demandas de las localidades. 
Sociologias, Porto Alegre, ano 16, no 37, set/dez 2014, p. 72-111

Además de reconocer gran parte de los postulados de la nueva economía en el patrón alternativo, en Argentina el Estado y la preservación de lo público fue protagónico en todos los patrones a la hora de plantearse tránsitos hacia consumos sustentables de agua y energía en minería, así como para evitar estos consumos.

Nuestra presentación de ambas controversias a partir de dos proyectos argentinos mostró cuán polémico es para los actores y las agencias identificadas concebir los complejos agua-energía-minería, y por tanto, cuán distantes estarían los supuestos sobre la existencia de un sonambulismo tecnológico sobre la producción minera en Argentina, eso sí, nuestras evidencias nos plantearon escasas e incipientes iniciativas donde poder situar a grupos ciudadanos argentinos verdes proponiendo transformaciones en los patrones de consumo de metales transnacionales hacia vías más sustentables o alternativas.

Aunque nuestro propósito no se abocó al análisis comparado entre patrones de consumo sustentable particulares en minería Sudamerica$\mathrm{na}^{14}$, y más bien proseguimos evidencias sobre la posibilidad de transformar e incluso evitar la explotación de metales a cielo abierto, esperamos que los resultados de este estudio sirvan como herramienta heurística para entender ciertas aristas de controversias y conflictos por el consumo de agua y energía de estas tecnologías en el marco de prever limitantes y posibilidades en el tránsito hacia vías de consumo sustentable en minería bajo la gobernanza ambiental argentina en particular, la cual esperamos proseguir en Sudamérica.

Gloria Baigorrotegui. Licenciada en Ciencias de la Ingeniería, Universidad de Santiago de Chile. Diplomada en Estudios Empresariales y Comercio Internacio-

\footnotetext{
${ }^{14}$ Para una presentación comparada de patrones de consumo en un estudio sudamericano ver Parker et al. (2013).
} 
Sociologias, Porto Alegre, ano 16, no 37, set/dez 2014, p. 72-111

nal, Universidad de Barcelona, España. Doctora en Filosofía, mención Estudios Sociales de la Ciencia y la Tecnología, Universidad del País Vasco, España.

$\gg$ gloria.baigorrotegui@usach.cl

Cristian Parker. Licenciado en Sociología, Universidad Católica de Chile. Licenciado en Ciencias del Desarrollo, Instituto Latinoamericano de Doctrina y Estudios Sociales. Doctor en Sociología, Universidad Católica de Lovoina, Bélgica.

$>$ cristian.parker@usach.cl

Fernando Estenssoro. Doctor en Estudios Americanos, Universidad de Santiago de Chile. Magíster en Ciencia Política. Mención Instituciones y Procesos. Pontificia Universidad Católica de Chile. $\gg$ fernando.estenssoro@usach.cl

\section{Referencias}

1. ALUMBRERA. Minería Alumbrea. Disponible en: <http://www.alumbrera. com.ar/>. Consultado el: 3 Septiembre 2014.

2. ÁMBITO FINANCIERO. Queja de mineras por pedido de aporte extra en Santa Cruz. Nota de Sabrina Pont aparecida el 5 jun. 2012. Disponible en: <http:// ambito.com/diario/noticia.asp?id=639827>. Consultado el: 19 dic. 2013.

3. ANGLOGOLD-ASHANTI. Argentina. Disponible en: <www.anglogold.com/ NR/...EA3C.../Argentina.pdf > . Consultado el: 23 dic. 2013.

4. ANTONELLI, M. Minería trasnacional y dispositivos de intervención en la cultura. La gestión del paradigma hegemónico de la minería responsable y el desarrollo sustentable. In: SVAMAPA, M.; ANTONELLI (Eds.), p. 51-102, 2010.

5. BAIGORROTEGUI, G. Socio-environmental conflict in the construction of a power plant in Spain's Basque Country: strategies, expertise and certifications. The International Journal of Justice and Sustainability, Septembre, 2013.

6. BAKER, L. Power Shifts in South Africa's Minerals-Energy Complex: From Coal Crunch to Wind Rush? Paper for Political Economy and the outlook for Capitalism, Congress, 5-7 july 2012, Paris, 2012.

7. BEBBINGTON, A. et al. Contention and ambiguity: Mining and the possibilities of development, Development and Change, v. 39, n.6, p. 887-914, 2008.

8. BGS - BRITISH GEOLOGICAL SURVEY. World Mineral Production 20072011. Keyworth, Nottingham: British Geological Survey, 2013. 
9. BIJKER, W.; HUGHES, T.; PINCH, T. (Ed.). The Social Construction of Technological Systems. New Directions in the Sociology and History of Technology. Cambridge: MIT Press, 1987.

10. BONASSO, M. El Mal, El modelo K y la Barrick Gold. Amos y Servidores en el saqueo de la Argentina. Buenos Aires: Planeta, 2011.

11. BÖHM, S.; MISOCZKY, M.; MOOG, S. Greening Capitalism? A Marxist Critique of Carbon Market. Organization Studies, pp. 1-22, 2012.

12. BRUZZONE, E. Minería Argentina. Buenos Aires: Biblos, 2012.

13. CAROSIO, A. El consumo en la encrucijada ética. Utopía y praxis latinoamericana: Revista internacional de filosofía iberoamericana y teoría social, n. 41, p. 13-45, 2008.

14. CASTELLS, M. La Sociedad en red: una visión global. Madrid:Alianza, 2006.

15. COHEN, M. ; MURPHY, J. Exploring sustainable consumption: environmental policy and the social sciences. Inversores europeos interesados en minería argentina 27/03/12. Disponible en: <https://mail.google.com/mail/u/0/\#search/ inversor + minero/13dac2e5ebead8a2 > Consultado el: 2 marzo 2013.

16. DAHL, R. Green washing. Do you know what you're buying? Environmental Health Perspectives, v. 118, n. 6, p. A246-A252, 2010.

17. EL INVERSOR MINERO. Inversores europeos interesados en minería argentina, 27/03/12. Disponible en: <https://mail.google.com/mail/u/0/\#search/in versor + minero/13dac2e5ebead8a2 > Consultado el: 2 marzo 2013.

18. ELZEN, B. et al. Normative contestation in transitions 'in the making': animal welfare concerns and system innovation in pig husbandry (1970-2008). Research Policy, n. 40, p. 263-275, 2011.

19. ESCALONA, D. et al. Justicia Ambiental y gran Minería. La discriminación de las comunidades. Santiago: Observatorio Latinoamericano de Conflictos Ambientales (OLCA), 2011.

20. ESTENSSORO, F. Medio ambiente e Ideología. São Paulo: EPU, 1989.

21. EVANS, N.; MORRIS, C.; WINTER, M. Conceptualizing agriculture: a critique of post-productivism as the new orthodoxy. Progress in Human Geography, n. 26, p. 313-332, 2002.

22. FIGUEIREDO, V. Produção Social da Tecnologia. São Paulo: EPU, 1989.

23. FRANKS, D. et al. Sustainable development principles for the disposal of mining and mineral processing wastes. Resources Policy, v. 33, n. 2, p. 114-122, jun. 2011.

24. GEELS, F. The multi-level perspective on sustainability transitions: responses to seven criticisms. Environmental Innovation and Societal Transitions, v. 1, n. 1, p. 24-40, jun. 2011. 
25. GEELS, F.; VERHEES, B. Cultural legitimacy and framing struggles in innovation journeys: a cultural-performative perspective and a case study of Dutch nuclear energy (1945-1986). Technological Forecasting and Social Change, n. 78, 2011.

26. GEELS, F.; SHOT, J. Typology of sociotechnical transition pathways. Research Policy, v. 36, n. 3, p. 825-842, 2007.

27. GEELS, F. Co-evolution of technology and society: the transition in water supply and personal hygiene in the Netherlands (1850-1930) a case study in multilevel perspective. Technology in Society, v. 27, n. 3, p. 363-397, 2005.

28. GEELS, F. Technological Transitions as evolutionary reconfiguration processes: a multi-level perspective and a case-study. Research Policy, n. 31, p. 1257-1274, 2002.

29. GUDYNAS, E. The new extractivism of the $2 \mathbf{1}^{\text {st }}$ Century. Ten urgent theses about extractivism in relation to current South American Progressivism. Americas Policy Program Report. Washington, DC: Center for International Policy, 2010.

30. HOGENBOOM, B. Depoliticized and Repoliticized Minerals in Latin America. Journal of Developing Societies, v. 28, n. 2, p. 133-158, 2012.

31. KEMP, D. et al. Mining, water and human rights: making the connection. Journal Cleaner Production,v. 18, n. 15, p. 1553-1562,2010.

32. LIM, W. et al. What happens when consumers realise about green washing? A qualitative investigation. International Journal of Global Environmental,v. 13, n. 1, p.14-24, 2013.

33. LOREK, S.; SPANGENBERG, J. Sustainable consumption within a sustainable economy beyond green growth and green economies. Journal of cleaner production 63, 33-44, 2014.

34. MACHADO, $\mathrm{H}$. et al.15 mitos y realidades de la minería transnacional en la Argentina. Guía para desmontar el imaginario pro minero. Buenos Aires: Colectivo Voces de Alerta y Ediciones Herramienta, 2011.

35. MACHADO, H. Minería Trasnacional, conflictos socioterritoriales y nuevas dinámicas expropiatorias. In: SVAMPA, M.; ANTONELLI, M. (Eds.) Minería Transnacional, narrativas de desarrollo y resistencias sociales. Buenos Aires: Biblos, 2005-220, 2010.

36. MARTINEZ-ALIER, J. et al. Social Metabolism, Ecological Distribution Conflicts and Valuation Languages. Ecological Economics, v. 70, n. 2, p. 153-158, 2010.

37. MAcKINNON, D. Reconstructing scale: towards a new scalar politics. Progress in Human Geography, v. 35, n. 1, p. 21-36, 2011.

38. MIRANDA, A. ¿Una ética para la Civilización Tecnológica? Posibilidades y límites del principio de la Responsabilidad de Hans Jonas.[S.I.]: Editorial Académica Español, 2012. 
Sociologias, Porto Alegre, ano 16, no 37, set/dez 2014, p. 72-111

39. MOUFFE, C. En torno a lo político. Buenos Aires: FCE, 2009.

40. MOULIAN, T. Chile Actual: Anatomía de un mito. Santiago: LOM, 2002.

41. OCMAL - OBSERVATORIO DE CONFLICTOS MINEROS DE AMERICA LATINA. Legislación Minera en el Derecho Comparado: los Casos de Chile, Ecuador, Perú, Guatemala y el Salvador. Observatorio Latinoamericano de Conflictos Mineros, FEDEPAZ. Disponible en: < file:///C:/Windows/system32/config/systemprofile/Documents/Downloads/Derecho_comparado_OCMAL.pdf > . Consultado el: 3 Septiembre 2014.

42. OLCA - OBSERVATORIO LATINOAMERICANO DE CONFLICTOS AMBIENTALES (Eds.). Minería al límite. Análisis de tres casos de minería de frontera en América Latina. Santiago: OLCA, 2011.

43. PANORAMA MINERO. La Presidenta inauguró una nueva explotación subterránea en Cerro Vanguardia. Disponible en: <www.panoramaminero.com.ar/ noti777.htm >. Consultado el: 3 Abril 2014.

44. PARKER, C.; BAIGORROTEGUI, G.; ESTENSSORO, F. Actores estratégicos y consumo sustentable (representaciones sociales e institucionales de consumo de agua y energía en el sector minero de países selectos en Sudamérica. Informe de Investigación D4.3. Proyecto Séptimo Programa Marco Engov 266710, 2013.

45. PARKER, C.; MUÑOZ, J. Elites universitarias y cambio climático. Ambiente \& Sociedade, v. XV, n. 2, p. 195-218, 2012.

46. PORTILHO, F. Sustentabilidade Ambiental, Consumo e Cidadania, Sao Paolo, Cortez Editora, 2005.

47. RITZER, G. The McDonalization of Society. Thousand Oaks: Pine Forges Press, 1996

48. ROBLetO,M.;MARCELO, W. Deuda Ecológica. Santiago de Chile: IEP, 1992.

49. RODRÍGUEZ, J. Vienen por el oro. Las invasiones mineras 500 años después. Buenos Aires: Ciccus, 2009.

50. RUEDA, E. Precaución, Ciencia y Pluralismo: imperativos cognitivos-normativos en al evaluación y gestión de riesgos tecnológicos. Gobernar los riesgos. Ciencia y valores en la sociedad del Riesgo. Madrid: Biblioteca Nueva, 2004. p. 251-262.

51. SECRETARÍA DE MINERÍA. Oportunidades de Inversión. Presidenta de la Nación. Ministerio de Planificación Federal, Inversión Pública y Servicios, Secretario de Minería. Buenos Aires: Presidencia de la República. Disponible en: < http:// www.mineria.gov.ar/pdf/informe-de-gestion.pdf> . Consultado el: 22 Enero 2014.

52. SEYFANG, G. The New Economics of Sustainable Consumption. Minería transnacional, narrativas del desarrollo y resistencias sociales. Buenos Aires: Biblos, 2009. 
Sociologias, Porto Alegre, ano 16, no 37, set/dez 2014, p. 72-111

53. SPÄTH, P.; ROHRACHER, H. "Energy Regions": The transformative power of regional discourses on socio-technical futures. Research Policy, v. 39, p. 449-458, 2010.

54. SVAMPA, M.; ANTONELLI, M. (Eds.) Minería Trasnacional, narrativas del desarrollo y resistencias sociales. Buenos Aires: Biblos, 2010.

55. SWYNGEDOUW, E.; KAIKA, M. Sustainability and Policy Innovation in a Multilevel Context. In: GETIMIS, P. et al. (Eds.). Participatory Governance in Multilevel Context: Concepts and Experience. Alemania: Leske\&Budrich, Opladen, 2002. p. 107-131.

56. TEIXEIRA DE BARROS, A. A visibilidade ambiental em perspectiva sociológica: estudo comparado Brasil-Portugal. Sociologias, Porto Alegre, v. 15, n. 33, p. 318-345, 2013.

57. THOMAS, H. Dinâmicas de inovação na Argentina (1970-1995).Abertura comercial, crise sistêmica e rearticulação. 1999. Tesis (Doctoral en Política Científica y Tecnológica) - Instituto de Geociências, Universidade Estadual de Campinas, Campinas, 1999.

58. TULA, F.; GIULIANO, G. Culturas Científicas y Alternativas Tecnológicas. Buenos Aires: Mincyt, 2010.

59. VACAREZZA, L. Conflicto en torno a una intervención tecnológica: Percepción del riesgo ambiental, conocimiento y ambivalencia en la explotación minera de Bajo de la Alumbrera. Revista CTS, v. 17, n. 6, p. 241-260, 2011.

60. WALTER, M.; MARTINEZ-ALIER J. How to Be Heard When Nobody Wants to Listen: the Esquel mining conflict. Canadian Journal of Development Studies, v. 30, n. 1-2, p. 281-303, 2010.

61. WBCSD. Eco-efficiency learning module, World Business Council for Sustainable Development, 2013.

62. WINNER, L. La Ballena y el Reactor. Una búsqueda de los límites en la era de la alta tecnología. Barcelona: Gedisa, 2008.

63. XSTRATA COPPER. Minera Alumbrera Informe de Sostenibilidad 2013. Buenos Aires: Xstrata, 2013.

64. XSTRATA COPPER. Minera Alumbrera. Informe de Sostenibilidad 2011. Buenos Aires: Xstrata, 2011.

65. YAÑEZ, N.; MOLINA, R. La gran minería y los derechos indígenas en el norte de Chile. Santiago: LOM, 2008.

Recebido em: 23/01/2014

Aceite final: 07/07/2014 